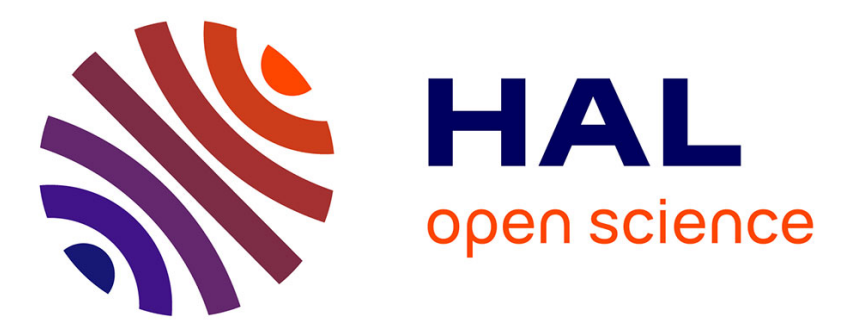

\title{
Towards Adaptive Robotic Green Plants
}

Janine Stocker, Aline Veillat, Stéphane Magnenat, Francis Colas, Roland Siegwart

\section{To cite this version:}

Janine Stocker, Aline Veillat, Stéphane Magnenat, Francis Colas, Roland Siegwart. Towards Adaptive Robotic Green Plants. Towards Autonomous Robotic Systems, 2011, Sheffield, United Kingdom. pp.422-423, 10.1007/978-3-642-23232-9_58. hal-01142611

\section{HAL Id: hal-01142611 \\ https://hal.science/hal-01142611}

Submitted on 15 Apr 2015

HAL is a multi-disciplinary open access archive for the deposit and dissemination of scientific research documents, whether they are published or not. The documents may come from teaching and research institutions in France or abroad, or from public or private research centers.
L'archive ouverte pluridisciplinaire HAL, est destinée au dépôt et à la diffusion de documents scientifiques de niveau recherche, publiés ou non, émanant des établissements d'enseignement et de recherche français ou étrangers, des laboratoires publics ou privés. 


\title{
Towards adaptive robotic green plants
}

\author{
Janine Stocker ${ }^{1}$, Aline Veillat ${ }^{2}$, Stéphane Magnenat ${ }^{1}$, Francis Colas $^{1}$, and \\ Roland Siegwart ${ }^{1}$ \\ 1 Autonomous Systems Lab. - ETH Zurich, Tannenstr. 3, 8092 Zürich, Switzerland \\ janine dot stocker at gmail dot com and firstname.lastname@mavt.ethz.ch \\ 2 aveillat at hotmail dot com
}

Humans often use green plants as furniture in their built environments. More generally, the status of plants as living beings is highly dependent on their lack of mobility. The goal of this project, which is a collaboration between artists and roboticists, is to lead the general public to a questioning about the role of plants in the society through an artistic installation. We do so by endowing a green plant with motion, perception, learning and adaptation capabilities while retaining the emotional characteristic of a plant, such as calm and gently random behaviours.

Several existing works involve green plants and robotics. For instance, [6] builds a "fake" plant mimicking the behaviour of a real one. In [2], a group of robots based on the iRobot Create manage a garden, caring for the plants.

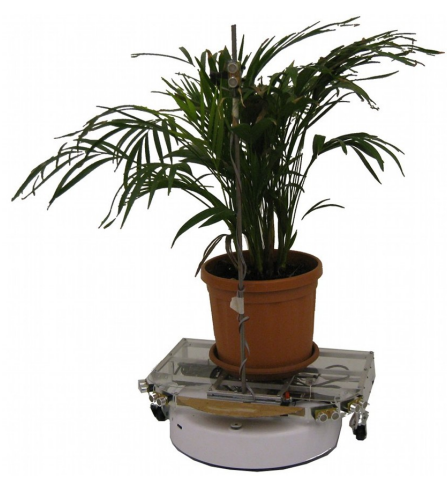
More into the artistic direction, [5] demonstrates a robotic flower pot moving imperceptibly slowly, and thus mimicking this particular attribute of green plants, that is, the slow reaction to the environmental changes. In this paper, the plant adapts its behaviour using a genetic algorithm. In this direction, previous works have emphasized the importance of adaptation [4] and the implied "play" behaviour [1] to create interesting robots from an artistic point of view. At the level of interaction, works have shown that an artistic robot should have its own life, avoiding or ignoring humans [3].

In this work, we propose a cyborg, that is, an agent combining biological and technological elements. This cyborg consists of an iRobot Create, a computer running Linux, a normal plant and additional sensors (Fig. 1). The final version will also feature a casing hiding the electronics. The cyborg lives its own life, following its internal needs of water, sunlight and electrical energy. It satisfies these needs by performing actions to fetch water, to find sunny locations and to recharge the robot's battery. To do so, and in contrast with existing works, the robot employs a well-founded probabilistic planning algorithm. This algorithm takes as input the current state of the cyborg needs, and produces as output a sequence of actions. 
The planning consists of optimizing the expected fitness value of the cyborg's needs at a certain time in the future, given a probabilistic model of the effect of actions on needs. To do so, the algorithm enumerates the possible action sequences of a certain length, and for each estimates the final fitness value. If a sequence would lead the cyborg into starvation (an empty battery), the sequence is discarded. Then, the sequence resulting in the best value is selected. The cyborg adapts by online learning the model of the effect of actions on needs.

Currently, the prototype of the cyborg is performing its tasks over several battery cycles. The cyborg avoids obstacles using ultrasonic sensors, finds the best light spot using light sensors and goes to a recharge and to a mock-up water station using iRobot's infrared sensor. We have conducted experiments by implementing the probabilistic model using histograms: for each type of action, we track the probability distribution of the state change. As needs are independent, we have one histogram per need per action. This model allowed the robot to run continuously for durations up to 28 hours, while alternating behaviours in an interesting way from an artistic point of view. In the future, we will include other actions, for instance in the context of group behaviours with multiple cyborgs. Indeed, one of the artistic goals is to run several cyborgs at an art exhibition.

An adaptive robotic green plant provides a simple application scenario for the development of simultaneous planning and learning algorithms. The implementation of such an algorithm allows a robotic plant to perform autonomously during a long period of time and enables its deployment in an art exhibition. On the artistic level, by endowing green plants with animal-level autonomy while keeping plant-level goals and drives, we expect interesting reactions from the general public. Ultimately, we hope to awake questions about the role of plants in the society, and to highlight their presence as actors in the world.

\section{References}

1. Arata, L.: Can your autonomous robot come out and play? In: Integration of Knowledge Intensive Multi-Agent Systems, 2003. International Conference on. pp. 14-18. IEEE Press (2003)

2. Correll, N., Arechiga, N., Bolger, A., Bollini, M., Charrow, B., Clayton, A., Dominguez, F., Donahue, K., Dyar, S., Johnson, L., et al.: Building a distributed robot garden. In: Intelligent Robots and Systems, 2009. IROS 2009. IEEE/RSJ International Conference on. pp. 1509-1516. IEEE Press (2009)

3. Fujita, M., Kotani, K., Kawaguchi, Y.: Artistic concept for negative-style interaction robotics. In: International Conference on Artificial Reality and Telexistence. pp. 240-245. IEEE Computer Society (2006)

4. García, R.P., Aróstegui, J.M.M.: A cooperative robotic platform for adaptive and immersive artistic installations. Computers \& Graphics 31(6), 809-817 (2007)

5. Mondada, F., Legon, S.: Interactions between art and mobile robotic system engineering. Evolutionary Robotics. From Intelligent Robotics to Artificial Life pp. 121-137 (2001)

6. Park, H., Jung, S., Choi, J., Park, S., Yoon, C., Park, J.: A study on the moving mechanism for flower robot. In: Control, Automation and Systems, 2007. ICCAS'07. International Conference on. pp. 2514-2518. IEEE Press (2007) 